\title{
Breast milk composition and infant nutrient intakes during the first 12 months of
}

life

Grote $\mathrm{V}^{1}$, Verduci $\mathrm{E}^{2}$, Scaglioni $\mathrm{S}^{2}$, Vecchi $\mathrm{F}^{2}, \mathrm{G}_{\text {Contarini }}^{3}$, Giovannini $\mathrm{M}^{2}$, Koletzko $\mathrm{B}^{1}$ $(\bowtie)$, Agostoni $C^{4}$, for the European Childhood Obesity Project*

${ }^{1}$ Div. Metabolic and Nutritional Medicine, Dr. von Hauner Children`s Hospital, Univ. of Munich, Medical Centre, Munich, Germany; ${ }^{2}$ Dept. of Pediatrics, San Paolo Hospital, University of Milan, Italy; ${ }^{3}$ CRA Agricultural Research Council (CRA-FLC), Lodi, Italy; ${ }^{4}$ Pediatric Clinic, Fondazione IRCCS Ospedale Maggiore Policlinico, DISCCO Department, University of Milan, Italy

Running title: Breast milk and nutrient intakes of term infants

Funding: The studies reported herein have been carried out with partial financial support from the Commission of the European Community, specific RTD Programme "Quality of Life and Management of Living Resources", within the 5th Framework Programme, research grants no. QLRT-2001-00389 and QLK1-CT-2002-30582, and the 6th Framework Programme, contract no. 007036 and the European Union's Seventh Framework Programme (FP7/2007-2013), project EarlyNutrition under grant agreement $n^{\circ} 289346$. This manuscript does not necessarily reflect the views of the Commission and in no way anticipates the future policy in this area. The formula for the study was produced by Bledina (Villefranchesur-Saône Cédex, France, part of Danone Baby Nutrition), who operated as a partner of this EU project and received a grant from the EU Commission for this task. No funding bodies had any role in study design, data collection and analysis, decision to publish, or preparation of the manuscript.

Address reprint requests and correspondence to:

Prof. Berthold Koletzko, Div. Metabolic and Nutritional Medicine, Dr. von Hauner Children's Hospital, University of Munich Medical Centre, Lindwurmstrasse 4, D- 
80337 Munich, Germany;

Phone: +49 894400 52826, Fax: +49 (0)89 4400 57944;

E-mail: office.koletzko@med.uni-muenchen.de

Trial Registration: ClinicalTrials.gov Identifier: NCT00338689;

URL: http://clinicaltrials.gov/ct2/show/NCT00338689?term=NCT00338689\&rank=1

Conflict of interest: The authors declare no conflict of interest. 


\section{Abstract}

\section{Objectives:}

The objective of this study was to quantify human milk supply and intake of breastfed infants up to age 12 months. Additionally, human milk composition was quantified per energetic macronutrient and fatty acid composition in a subsample of lactating mothers.

\section{Methods:}

174 Italian breastfed children were followed using test-weighing and 3-day food protocols from birth to age twelve months. From a sub-sample of thirty mothers breast milk samples were collected at child ages one (T1), two (T2), three (T3), and six (T6) months, and were analyzed for the amount of protein, digestible carbohydrates, total lipids and fatty acid composition.

\section{Results:}

$142(82 \%)$ filled in at least one three-day food protocol within the first 12 months of life and complied with test- weighing of all milk feeds. The number of valid food protocols declined from 126 infants at one month to 77 at twelve months of age. Only galactose, non-protein nitrogen and protein decreased significantly from age one to age six months of lactation. Maternal BMI and age affected fatty acid levels in human milk. Median human milk intake decreased from $625 \mathrm{ml}$ at $\mathrm{T} 1$, over $724 \mathrm{ml}$ at T3 to $477 \mathrm{ml} /$ day at $\mathrm{T} 6$. Average energy and \%energy from protein intake per day increased from $419 \mathrm{kcal}$ (SD 99) and $8.4 \%$ (1.0) at T1, respectively, to $860 \mathrm{kcal}(145)$ and $16.1 \%(2.6)$ at T12.

\section{Conclusion:}

These data provide a reference range of nutrient intakes in breastfed infants and may provide guidance for defining optimal nutrient intakes for infants that cannot be fully breastfed. 


\section{Introduction}

Infants should be exclusively breastfed during the first months of life with continued breastfeeding after timely introduction of complementary feeding ${ }^{1}$. In addition to providing a generally adequate nutrient supply that supports normal growth and development, breastfeeding has been linked to multiple other advantages including a reduced risk of infections and long-term benefits for the risk of obesity, type 2 diabetes, blood pressure and better performance in intelligence tests ${ }^{2}$. Information on the nutrient supply of breastfed infants is of interest because if provides guidance for defining adequate nutrient intake of infants ${ }^{3-5}$.

Human milk composition and breast milk intake have been reported in several studies ${ }^{6-}$ ${ }^{10}$. However, only few studies reported both breast milk volume consumed and milk nutrient composition, and in particular most data on human milk fatty acid supply are limited to the first weeks of life ${ }^{11,12}$. Moreover, inter- and intra-individual persistence of milk composition or the degree of changes over time is not well described. These data may become relevant to check their relation with health outcomes.

Aim of the present paper is to quantify human milk intake and human milk nutrient content (energy-delivering macronutrients and fat composition) in a contemporary European Italian population of mother-infants pairs longitudinally followed up through the first year of life. 


\section{Subjects and Methods}

\section{Design and study population}

The data of the study population were collected and evaluated within the framework of the European Childhood Obesity Project, a multicenter double-blind intervention trial in five European countries with an observational group of breastfed infants and two intervention groups of formula fed infants (FF). The primary objective of the trial was to investigate the effect of infant protein supply on growth and obesity risk. Details of the

study were reported previously ${ }^{13,14}$. Data reported herein are based on Italian children with test weighing before and after breastfeeding.

Healthy, term infants born after uncomplicated pregnancies were recruited in maternity hospitals in the first 8 weeks of life between October 2002 and July 2004. Children were excluded for non-compliance if formula was given more than $10 \%$ of all feedings or they were fed $\geq 3$ bottles of formula per week in the first 3 months of life. Mothers were encouraged not to introduce any complementary food before the age of 4 completed months. Birth weight and length were obtained from hospital data, while all other anthropometric data were measured at visits at the study center at baseline (median age 14 days; interquartile range 12, 16 days) and the ages of 3,6 and 12 months. Anthropometric data were also expressed as z-scores relative to the growth standards of the $\mathrm{WHO}^{15}$.

Data on the course of pregnancy, medical history, and socioeconomic background were recorded at baseline. Maternal BMI was calculated from self-reported pre-pregnancy weight and the first available height measurement of the mother after study entry.

\section{Breast milk sampling}

Between October 2002 and March 2003 a sub-sample of thirty lactating mothers collected breast milk samples at child ages one (T1), two (T2), three (T3), and six (T6) months. Over three days samples of breast milk were taken from the first feeding in the 
morning after the mother got up. Mothers were instructed to manually express $10 \mathrm{ml}$ samples of milk from the breast the infant was fed on, both at the beginning (foremilk) and at the end of each feed (hindmilk). Each sample was collected in a sterile vial and frozen at home at about $-20^{\circ} \mathrm{C}$. After the third day the collected samples were delivered in a cooler to the Dept. of Pediatrics, San Paolo Hospital, Milan. There the collected aliquots were further stored at $-20^{\circ} \mathrm{C}$. Analysis within three months after collection was then carried out by pooling equal volumes of fore- and hind-milk.

\section{Analysis of milk samples}

Milk samples were analyzed for the content of protein, non-protein nitrogen, total digestable carbohydrates, lactose, glucose, galactose, total lipids and fatty acid composition (FA). Total protein (TP) content was evaluated by a modified turbidimetric Kingsbury method (Milk screen, Callegari, Italy) ${ }^{16}$. Protein nitrogen (PN) was derived by dividing TP by 6.38. Total nitrogen (TN) was evaluated with the Kjeldahl method. Nonprotein nitrogen (NPN) was calculated as follows: NPN=TN- PN.

Total digestible carbohydrate content (without human milk oligosaccharides), lactose, glucose and galactose were quantified by high-performance liquid chromatography (HPLC) using a Thermo Finningan Surveyor HPLC System (Thermo Fisher Scientific Inc, Waltham, MA, USA), with aAminex HPX-87 column (Bio-Rad Laboratories, Richmond, CA, USA) ${ }^{17}$.

Total lipids were extracted according to the method of Folch et al. ${ }^{18}$. Fatty acids (FA) in extracted milk lipids were transferred into their methyl esters with acid catalysis and quantified by gas chromatography. Milk phospholipids were quantified by assessment of inorganic phosphorus after separation of the phospholipid fraction by thin layer chromatography ${ }^{19}$. 
Information on total dietary intakes was collected in 3-day weighed food records. The information was collected monthly at 1 to 9 months and at 12 months of age.

Procedures and methods are described elsewhere ${ }^{14,20}$.

In order to quantify the daily milk intake during the 3-day weighed food records period, infants were weighed before and after each breastfeeding over those three days with the baby lying on an electronic scale (Sartorius AG, Göttingen, Germany) with clothes and diaper. The duration of the milk feeding was not recorded consistently. For infants of mothers with breastmilk samples (BFms), energy and macronutrient intake from human milk was based on the given human milk intake and individual breastmilk content in each analyzed month. To calculate energy and macronutrient intake in breastfed children without breastmilk samples, the median breastmilk content of the BFms group at each respective month was used to calculate nutrient intake from breastmilk. For those months without concurrent breastmilk sampling $(4,5,7,8,9,12$ months), the breastmilk content was substituted: at four months of age with breastmilk data from three months, and at five to twelve months by six months data.

\section{Statistics}

Breast milk data were plotted for all individuals and compounds over time to detect obvious outliers. We set implausible observations to missing for protein and calories $(n=1)$ and $n-3$ fatty acids $(n=3)$. Continuous data were generally displayed as means with standard deviation, in case of obvious skewness we used medians with interquartile range (IQR). To test for differences in general characteristics between children of mother with human milk data and those without we used a chi2-test or t-test as appropriate.

We used mixed models that account for repeated measures (random effect for subject and fixed effect for month) to determine if human milk constituents changed over time and to assess the impact of following factors on milk composition: maternal pre- 
pregnancy BMI, age, postnatal depression according to Edinburgh depression scale, caesarean section, smoking in pregnancy, marital status, education, and nationality; infant birth order, birth weight, gestational age, and gender. To account for multiple testing we used Bonferroni adjustment. Thus, we considered $p$ values $>0.00021$ to be significant, representing the $\alpha=0.05$ limit. We used the same method and set of variables to look for an impact on caloric intake by any of these factors.

\section{Ethics}

The study was approved by the Italian ethics committee of San Paolo Hospital, Milan. Written informed consent was obtained by the mothers. 


\section{Results}

174 breastfed infants and their mothers were enrolled into the study. Human milk content or at least one food protocol within the first 12 months of life with valid test weighing of all breast milk feeds during a given day were available in 142 infants (82\%). All infants were breastfed ad libitum on demand. In the subgroup of 30 subjects with breast milk collections at 1, 2, 3, and 6 months of age, we had no concurrent food protocols in one child. The number of evaluable food protocols per month declined from 126 infants at age one month to 83 at six and 77 at 12 months.

Mother and infant characteristics as well as socio-demographic descriptors of the study population are shown in Table 1. There were no major differences between those 30 mother-infant pairs with a breast milk sample (BFms) and those 107 without (BF). However, BFms mothers were significantly more often of Italian nationality ( $97 \%$ vs. $83 \% ; p=0.004)$ and introduced solids somewhat later than BF children $(p=0.030)$.

\section{Human milk composition}

Milk composition measured are shown in Table 2. The contents of protein, non-protein nitrogen and galactose decreased significantly between one and six months of lactation. None of the other measured parameters changed significantly over time, although there was a trend towards decreasing contents of energy and fat.

Age and pre-pregnancy BMI of the mother were the only discernible factors that had an impact on the milk composition. Polyunsaturated fatty acids, linoleic acid and total omega 6 fatty acids were all significantly $($ all $p<0.0001)$ lower in older than in younger mothers. The average proportion of polyunsaturated fatty acids of total lipids, for instance, decreased from $20 \%$ (age < 28 years) over 16\% (28-32 years) to 14\% (>33 years). MUFA, on the other hand, were lower $(p=0.0002)$ in mothers with higher prepregnancy BMI: 41\% (BMI >=25 kg/m²) versus $47 \%\left(<25 \mathrm{~kg} / \mathrm{m}^{2}\right)$. 
Additionally, EPA, DHA, MUFA, n-3 LC PUFA and the $n-3 / n-6$ ratio were higher, and $\alpha-$ Linolenic acid were lower on older mothers ( $p$ value $<0.05$ ). Furthermore, energy, fat, protein and galactose content was higher in mothers with higher BMI ( $p$ value $<0.05$ ). However, all these differences were not significant after correcting for multiple testing.

Human milk, energy, macronutrient and fatty acid intake

Table 3 presents the number of all breastfed children with 3-day food protocols available per month and macronutrient intakes. Intake from other nutritional sources than human milk was negligible in the first three months of life. Concordant with the introduction of complementary feeding the overall intake from human milk declined from 4 months onwards (Figure 1). While the energy intake from protein decreased until the start of complementary feeding with declining protein content of human milk, it more than doubled between 4 and 12 months of age (Figure 2). Protein made up about 18\% of the energy intake at 12 months of age. Energy intake was $77-79 \mathrm{kcal} / \mathrm{kg}$ bodyweight per day at 3 and 6 months and increased to $91 \mathrm{kcal} / \mathrm{kg}$ per day at 12 months. Besides current weight there were no discernible factors that influenced caloric intake during the first year of life (data not shown).

Fatty acid intakes from human milk are outlined in Table 4 . There is a high variation in intakes. However, overall intakes are quite stable during months one to three but declined with the reduction in human milk intake.

The average intakes of infant with individual human milk data and those with estimated human milk composition were not significantly different (data not shown). 


\section{Discussion}

Our study provides prospectively collected data on human milk intake and the supply of selected key nutrients from human milk and other foods in a concurrent population of European infants during the first year of life. These data on nutrient intakes in an apparently healthy population may contribute to estimating adequate intake ranges for infants $^{21}$.

\section{Human Milk composition}

In general, data on the human milk composition, i.e. energy, protein, NPN, lactose and fat content, are consistent with previous observations ${ }^{22-25}$. There was a great variability in the composition between mothers and during lactation. As already observed ${ }^{10,22,23,}$ ${ }^{26}$, there was a gradual decrease in protein and non-protein nitrogen content until 6 months of age.

Free galactose made up only a small fraction of carbohydrates in human milk and significantly decreased over time. This is in line with the observation of somewhat higher concentrations in colostrum than in human milk at 4 months of age ${ }^{27}$. Much higher concentrations of galactose are found in formula milk ${ }^{28}$. However, there is no data on any biologic importance of this carbohydrate in human milk.

The fat content in our study is in the lower range of concentrations found in other studies ${ }^{11,22,29-31}$. Mean fat content of human milk may vary considerably between individuals as well as between study populations from affluent or developing countries ${ }^{31}$. Besides maternal factors like diet and weight gain during pregnancy, sampling procedures have a distinct impact on fat levels ${ }^{32}$. Fat concentration is increasing from fore- to hindmilk ${ }^{11}$. We collected fore- and hindmilk in approximately equal volumes to have an approximate real average fat concentration.

Whereas a high variability in human milk concentration is expected also for fatty acids ${ }^{33}$, concentrations in our population are similar to those reported in previous studies ${ }^{11,}$ 
12, 29, 32, 34-36. SFA concentrations were slightly lower and MUFA concentrations higher compared to other European and African studies ${ }^{34}$. This might be due to higher consumptions of olive oil as reported by Marangoni et al ${ }^{11}$. However, Antonakou et al found also lower levels of MUFA in a Greek population ${ }^{29}$.

Contents of individual n-3 and n- 6 LC-PUFA were fairly consistent with values of other studies ${ }^{11,12,34-36}$ and remained relatively stable over the six months. Docosahexaenoic (DHA) concentrations were comparably low. As DHA levels are quite sensitive to maternal diet ${ }^{29,34,37-39}$, nutritional intake in those lactating women might not have been optimal.

Studies relating maternal factors to human milk content are infrequent. We saw effects of maternal age and BMI on human milk composition, mainly fatty acids. Effects on lipid levels have been also observed by others ${ }^{22,31}$, however effects were not very consistent and changes in fatty acids are not described. In principal, there is a close relationship between human milk FA and maternal plasma $F A^{40}$ but the relationship of the latter with maternal BMI is unclear. As we see associations with essential and nonessential FA, any interpretation is not straightforward. Whereas parity has been previously described as an influential factor for lipids ${ }^{22}$, we did not find substantial evidence in previous studies that maternal age has a considerable impact on human milk composition. Thus, our findings should be interpreted with caution.

\section{Nutritional Intake}

Overall human milk consumption at 3 months was $10-15 \%$ lower than the average reported in one review ${ }^{41}$ and one study using stable isotope methods ${ }^{42}$ but was in the usual range of reported studies. Moreover, milk intake in our study can be estimated to be even $5 \%$ higher, as we did not correct our data for insensible water loss since feeding duration was not consistently measured in all infants ${ }^{42}$. As exclusive breastfeeding up to three months of age was requested as an inclusion criterion for the 
study, lower values at later ages can mainly be attributed to complementary foods. This is reflected in the continuous decrease in human milk intake from month four onwards. Total energy intake agrees with recommendations and previous reports ${ }^{43}$. Macronutrient composition of foods is shifting with the start of complementary feeding: the contribution of fat decreases and of protein increases. While the intake of fat falls below the recommended $40 \mathrm{E} \%{ }^{43}$, all infants still consumed fat above the lower acceptable limit ${ }^{44}$. At 3 months of age protein intake in our infants was approximately $30-45 \%$ lower compared to intakes of formula-fed children ${ }^{13,45}$. However, until 12 months of age average protein intake rose above the maximum acceptable limit of 15 $\mathrm{E} \%{ }^{46}$, with $70 \%$ of all children exceeding this limit. Considering that higher protein intakes may lead to a higher obesity risk at school age ${ }^{47}$, the excessive introduction of protein sources during complementary feeding needs to be critically evaluated. Polyunsaturated fatty acids (PUFAs), such as a-linolenic acid (ALA), linoleic acid (LA), and LC-PUFAs, are essential and should be supplied in sufficient quantities to guarantee normal visual and cognitive development during infancy ${ }^{48}$. Whereas the supply with omega-6 long-chain polyunsaturated fatty acid (LC-PUFA) can be considered adequate in our study ${ }^{43}$, the mean supply of omega-3 LC-PUFA DHA with human milk of around $50 \mathrm{mg} / \mathrm{d}$ up to 3 months of age and $33 \mathrm{mg} / \mathrm{d}$ at 6 months is markedly lower than the intake of $100 \mathrm{mg} / \mathrm{d}$ considered advisable ${ }^{43,49}$. A more regular consumption of ocean fish and seafood, including oily fish and bluefish by breastfeeding women would increase the DHA content of human milk and hence increase the supply to the breastfed infant ${ }^{50}$. Furthermore, fish consumption during complementary feeding is rare. We had no record of fish consumption during the first year of life.

\section{Strengths and limitations}

We presented data of human milk content and children's nutritional intake from a prospectively followed population of well-nourished contemporary European women 
consuming self-selected diets and their children. While the number of women with milk composition data was limited, the number of children with measured breastmilk intake was considerable larger. We had to extrapolate human milk composition from 6 months measurement to later time points. However, due to the decline in human milk consumption and the notion that the content of mature milk is relatively stable in the second half of the first year of life ${ }^{31}$, we do not suspect mayor bias due to this approach. Furthermore, individual data on human milk composition and infant intakes were only available in a subgroup of infants, reducing the inter-individual variation in intakes. However, mean intakes of infants with individual human milk data and those without were very similar.

\section{Conclusion}

Although supply with human milk alone does not allow the determination of suitability and safety of a similar supply with formula and other infant feeding, these data can contribute to the estimation of adequate nutrient intakes for populations of healthy infants. 


\section{References}

1. Agostoni C, Decsi T, Fewtrell M, Goulet O, Kolacek S, Koletzko B et al. Complementary feeding: a commentary by the ESPGHAN Committee on Nutrition. J Pediatr Gastroenterol Nutr 2008; 46(1): 99-110. e-pub ahead of print 2007/12/29; doi: 10.1097/01.mpg.0000304464.60788.bd

2. Nutrition ECo, Agostoni C, Braegger C, Decsi T, Kolacek S, Koletzko B et al. Breast-feeding: A commentary by the ESPGHAN Committee on Nutrition. $J$ Pediatr Gastroenterol Nutr 2009; 49(1): 112-125. e-pub ahead of print 2009/06/09; doi: 10.1097/MPG.0b013e31819f1e05

3. Hermoso M, Tabacchi G, Iglesia-Altaba I, Bel-Serrat S, Moreno-Aznar LA, Garcia-Santos $Y$ et al. The nutritional requirements of infants. Towards EU alignment of reference values: the EURRECA network. Matern Child Nutr 2010; 6 Suppl 2: 55-83. e-pub ahead of print 2010/10/01; doi: 10.1111/j.17408709.2010.00262.x

4. Koletzko B, Baker S, Cleghorn G, Neto UF, Gopalan S, Hernell O et al. Global standard for the composition of infant formula: recommendations of an ESPGHAN coordinated international expert group. J Pediatr Gastroenterol Nutr 2005; 41(5): 584-599.

5. Koletzko B, Bhutta ZA, Cai W, Cruchet S, El Guindi M, Fuchs GJ et al. Compositional requirements of follow-up formula for use in infancy: recommendations of an international expert group coordinated by the Early Nutrition Academy. Ann Nutr Metab 2013; 62(1): 44-54. doi: 10.1159/000345906

6. Heinig MJ, Nommsen LA, Peerson JM, Lonnerdal B, Dewey KG. Energy and protein intakes of breast-fed and formula-fed infants during the first year of life and their association with growth velocity: the DARLING Study. Am J Clin Nutr 1993; 58(2): 152-161.

7. Ferris AM, Dotts MA, Clark RM, Ezrin M, Jensen RG. Macronutrients in human milk at 2, 12, and 16 weeks postpartum. J Am Diet Assoc 1988; 88(6): 694-697. e-pub ahead of print 1988/06/01;

8. Butte NF, Garza C, Johnson CA, Smith EO, Nichols BL. Longitudinal changes in milk composition of mothers delivering preterm and term infants. Early Hum Dev 1984; 9(2): 153-162. e-pub ahead of print 1984/02/01;

9. Neville MC, Allen JC, Archer PC, Casey CE, Seacat J, Keller RP et al. Studies in human lactation: milk volume and nutrient composition during weaning and lactogenesis. Am J Clin Nutr 1991; 54(1): 81-92. e-pub ahead of print 1991/07/01;

10. Allen JC, Keller RP, Archer P, Neville MC. Studies in human lactation: milk composition and daily secretion rates of macronutrients in the first year of lactation. Am J Clin Nutr 1991; 54(1): 69-80. e-pub ahead of print 1991/07/01; 
11. Marangoni F, Agostoni C, Lammardo AM, Giovannini M, Galli C, Riva E. Polyunsaturated fatty acid concentrations in human hindmilk are stable throughout 12-months of lactation and provide a sustained intake to the infant during exclusive breastfeeding: an Italian study. Br J Nutr 2000; 84(1): 103-109. e-pub ahead of print 2000/08/29;

12. Agostoni C, Riva E, Scaglioni S, Marangoni F, Radaelli G, Giovannini M. Dietary fats and cholesterol in italian infants and children. Am J Clin Nutr 2000; 72(5 Suppl): 1384S-1391S. e-pub ahead of print 2000/11/04;

13. Koletzko B, von Kries R, Closa R, Escribano J, Scaglioni S, Giovannini M et al. Lower protein in infant formula is associated with lower weight up to age $2 \mathrm{y}$ : a randomized clinical trial. Am J Clin Nutr 2009; 89(6): 1836-1845. e-pub ahead of print 2009/04/24; doi: 10.3945/ajcn.2008.27091

14. Schiess S, Grote V, Scaglioni S, Luque V, Martin F, Stolarczyk A et al. Introduction of complementary feeding in 5 European countries. J Pediatr Gastroenterol Nutr 2010; 50(1): 92-98. e-pub ahead of print 2009/06/23; doi: 10.1097/MPG.0b013e31819f1ddc

15. WHO MGRSG. WHO Child Growth Standards based on length/height, weight and age. Acta Paediatr Suppl 2006; 450: 76-85. e-pub ahead of print 2006/07/05;

16. Shank RE, Hoagland CL. A modified method for the quantitative determination of the thymol turbidity reaction of serum. J Biol Chem 1946; 162: 133-138.

17. Kowalski ZE, Giesecke WH. A high performance liquid chromatographic method for the fluorimetric determination of lactose, galactose and glucose in normal and abnormal milk of cows. Onderstepoort J Vet Res 1986; 53(4): 225-229.

18. Folch J, Lees M, Sloane Stanley GH. A simple method for the isolation and purification of total lipides from animal tissues. J Biol Chem 1957; 226(1): 497509. e-pub ahead of print 1957/05/01;

19. Rouser G, Siakotos AN, Fleischer S. Quantitative analysis of phospholipids by thin-layer chromatography and phosphorus analysis of spots. Lipids 1966; 1(1): 85-86. e-pub ahead of print 1966/01/01; doi: 10.1007/bf02668129

20. Verwied-Jorky S, Schiess S, Luque V, Grote V, Scaglioni S, Vecchi F et al. Methodology for longitudinal assessment of nutrient intake and dietary habits in early childhood in a transnational multicenter study. J Pediatr Gastroenterol Nutr 2011; 52(1): 96-102. e-pub ahead of print 2010/12/15; doi: 10.1097/MPG.0b013e3181f28d33

21. Atkinson SA, Koletzko B. Determining life-stage groups and extrapolating nutrient intake values (NIVs). Food Nutr Bull 2007; 28(1 Suppl International): S61-76.

22. Nommsen LA, Lovelady CA, Heinig MJ, Lonnerdal B, Dewey KG. Determinants of energy, protein, lipid, and lactose concentrations in human milk during the first 
12 mo of lactation: the DARLING Study. Am J Clin Nutr 1991; 53(2): 457-465. epub ahead of print 1991/02/01;

23. Michaelsen KF, Larsen PS, Thomsen BL, Samuelson G. The Copenhagen Cohort Study on Infant Nutrition and Growth: breast-milk intake, human milk macronutrient content, and influencing factors. Am J Clin Nutr 1994; 59(3): 600611. e-pub ahead of print 1994/03/01;

24. Khan S, Hepworth AR, Prime DK, Lai CT, Trengove NJ, Hartmann PE. Variation in fat, lactose, and protein composition in breast milk over 24 hours: associations with infant feeding patterns. J Hum Lact 2013; 29(1): 81-89. e-pub ahead of print 2012/07/17; doi: 10.1177/0890334412448841

25. Quinn EA, Largado F, Power M, Kuzawa CW. Predictors of breast milk macronutrient composition in Filipino mothers. Am J Hum Biol 2012; 24(4): 533540. e-pub ahead of print 2012/03/22; doi: 10.1002/ajhb.22266

26. Bauer J, Gerss J. Longitudinal analysis of macronutrients and minerals in human milk produced by mothers of preterm infants. Clin Nutr 2011; 30(2): 215-220. epub ahead of print 2010/08/31; doi: 10.1016/j.clnu.2010.08.003

27. Coppa GV, Gabrielli O, Pierani P, Catassi C, Carlucci A, Giorgi PL. Changes in carbohydrate composition in human milk over 4 months of lactation. Pediatrics 1993; 91(3): 637-641.

28. Cavalli C, Teng C, Battaglia FC, Bevilacqua G. Free sugar and sugar alcohol concentrations in human breast milk. J Pediatr Gastroenterol Nutr 2006; 42(2): 215-221. doi: 10.1097/01.mpg.0000189341.38634.77

29. Antonakou A, Skenderi KP, Chiou A, Anastasiou CA, Bakoula C, Matalas AL. Breast milk fat concentration and fatty acid pattern during the first six months in exclusively breastfeeding Greek women. Eur J Nutr 2013; 52(3): 963-973. e-pub ahead of print 2012/07/04; doi: 10.1007/s00394-012-0403-8

30. Saarela T, Kokkonen J, Koivisto M. Macronutrient and energy contents of human milk fractions during the first six months of lactation. Acta Paediatr 2005; 94(9): 1176-1181. doi: 10.1080/08035250510036499

31. Michaelsen KF, Skafte L, Badsberg JH, Jorgensen M. Variation in macronutrients in human bank milk: influencing factors and implications for human milk banking. J Pediatr Gastroenterol Nutr 1990; 11(2): 229-239. e-pub ahead of print 1990/08/01;

32. Jensen RG. Lipids in human milk. Lipids 1999; 34(12): 1243-1271.

33. Stam J, Sauer PJ, Boehm G. Can we define an infant's need from the composition of human milk? Am J Clin Nutr 2013; 98(2): 521S-528S. doi: 10.3945/ajcn.112.044370 
34. Koletzko B, Thiel I, Abiodun PO. The fatty acid composition of human milk in Europe and Africa. J Pediatr 1992; 120(4 Pt 2): S62-70. e-pub ahead of print 1992/04/01;

35. EFSA NDA Panel (EFSA Panel on Dietetic Products NaA. Scientific Opinion on Dietary Reference Values for fats, including saturated fatty acids, polyunsaturated fatty acids, monounsaturated fatty acids, trans fatty acids, and cholesterol. EFSA Journal 2010; 8(3): 1461. doi: 10.2903/j.efsa.2010.1461

36. EFSA NDA Panel (EFSA Panel on Dietetic Products NaA. Scientific Opinion on the essential composition of infant and follow-on formulae. EFSA Journal 2014; 12(7): 3760. doi: 10.2903/j.efsa.2013.3408

37. Smit EN, Koopmann M, Boersma ER, Muskiet FA. Effect of supplementation of arachidonic acid (AA) or a combination of AA plus docosahexaenoic acid on breastmilk fatty acid composition. Prostaglandins Leukot Essent Fatty Acids 2000; 62(6): 335-340. e-pub ahead of print 2000/07/27; doi:

$10.1054 /$ plef.2000.0163

38. Patin RV, Vitolo MR, Valverde MA, Carvalho PO, Pastore GM, Lopez FA. The influence of sardine consumption on the omega- 3 fatty acid content of mature human milk. J Pediatr (Rio J) 2006; 82(1): 63-69. e-pub ahead of print 2006/03/15; doi: 10.2223/JPED.1439

39. Olafsdottir AS, Thorsdottir I, Wagner KH, Elmadfa I. Polyunsaturated fatty acids in the diet and breast milk of lactating icelandic women with traditional fish and cod liver oil consumption. Ann Nutr Metab 2006; 50(3): 270-276. e-pub ahead of print 2006/03/02; doi: 10.1159/000091685

40. Emken EA, Adlof RO, Hachey DL, Garza C, Thomas MR, Brown-Booth L. Incorporation of deuterium-labeled fatty acids into human milk, plasma, and lipoprotein phospholipids and cholesteryl esters. J Lipid Res 1989; 30(3): 395402.

41. Reilly JJ, Ashworth S, Wells JCK. Metabolisable energy consumption in the exclusively breast-fed infant aged 3-6 months from the developed world: a systematic review. Br J Nutr 2005; 94(1): 56-63. doi: 10.1079/bjn20051464

42. da Costa TH, Haisma H, Wells JC, Mander AP, Whitehead RG, Bluck LJ. How much human milk do infants consume? Data from 12 countries using a standardized stable isotope methodology. J Nutr 2010; 140(12): 2227-2232. doi: 10.3945/jn.110.123489

43. EFSA NDA Panel (EFSA Panel on Dietetic Products NaA. Scientific Opinion on nutrient requirements and dietary intakes of infants and young children in the European Union. EFSA Journal 2013; 11(10): 3408. doi:

10.2903/j.efsa.2013.3408 
44. IoM (Institute of Medicine). Dietary reference intakes for energy, carbohydrate, fiber, fat, fatty acids, cholesterol, protein, and amino acids, National Academies Press: Washington DC, USA, 2005.

45. Alexy U, Kersting M, Sichert-Hellert W, Manz F, Schoch G. Macronutrient intake of 3- to 36-month-old German infants and children: results of the DONALD Study. Dortmund Nutritional and Anthropometric Longitudinally Designed Study. Ann Nutr Metab 1999; 43(1): 14-22.

46. Agostoni C, Scaglioni S, Ghisleni D, Verduci E, Giovannini M, Riva E. How much protein is safe? Int $J$ Obes 2005; 29: S8-S13.

47. Weber M, Grote V, Closa-Monasterolo R, Escribano J, Langhendries JP, Dain E et al. Lower protein content in infant formula reduces $\mathrm{BMI}$ and obesity risk at school age: follow-up of a randomized trial. Am J Clin Nutr 2014; 99(5): 10411051. doi: 10.3945/ajcn.113.064071

48. Koletzko B, Lien E, Agostoni C, Bohles H, Campoy C, Cetin I et al. The roles of long-chain polyunsaturated fatty acids in pregnancy, lactation and infancy: review of current knowledge and consensus recommendations. J Perinat Med 2008; 36(1): 5-14. doi: 10.1515/JPM.2008.001

49. Koletzko B, Boey CC, Campoy C, Carlson SE, Chang N, Guillermo-Tuazon MA et al. Current information and Asian perspectives on long-chain polyunsaturated fatty acids in pregnancy, lactation, and infancy: systematic review and practice recommendations from an early nutrition academy workshop. Ann Nutr Metab 2014; 65(1): 49-80. doi: 10.1159/000365767

50. Fidler N, Sauerwald T, Pohl A, Demmelmair H, Koletzko B. Docosahexaenoic acid transfer into human milk after dietary supplementation: a randomized clinical trial. J Lipid Res 2000; 41(9): 1376-1383. 
Figure 1: Energy and protein intake from all foods and from breastmilk during the first year of life. Boxplots with median and interquartile ranges, upper and lower adjacent values and outliers.
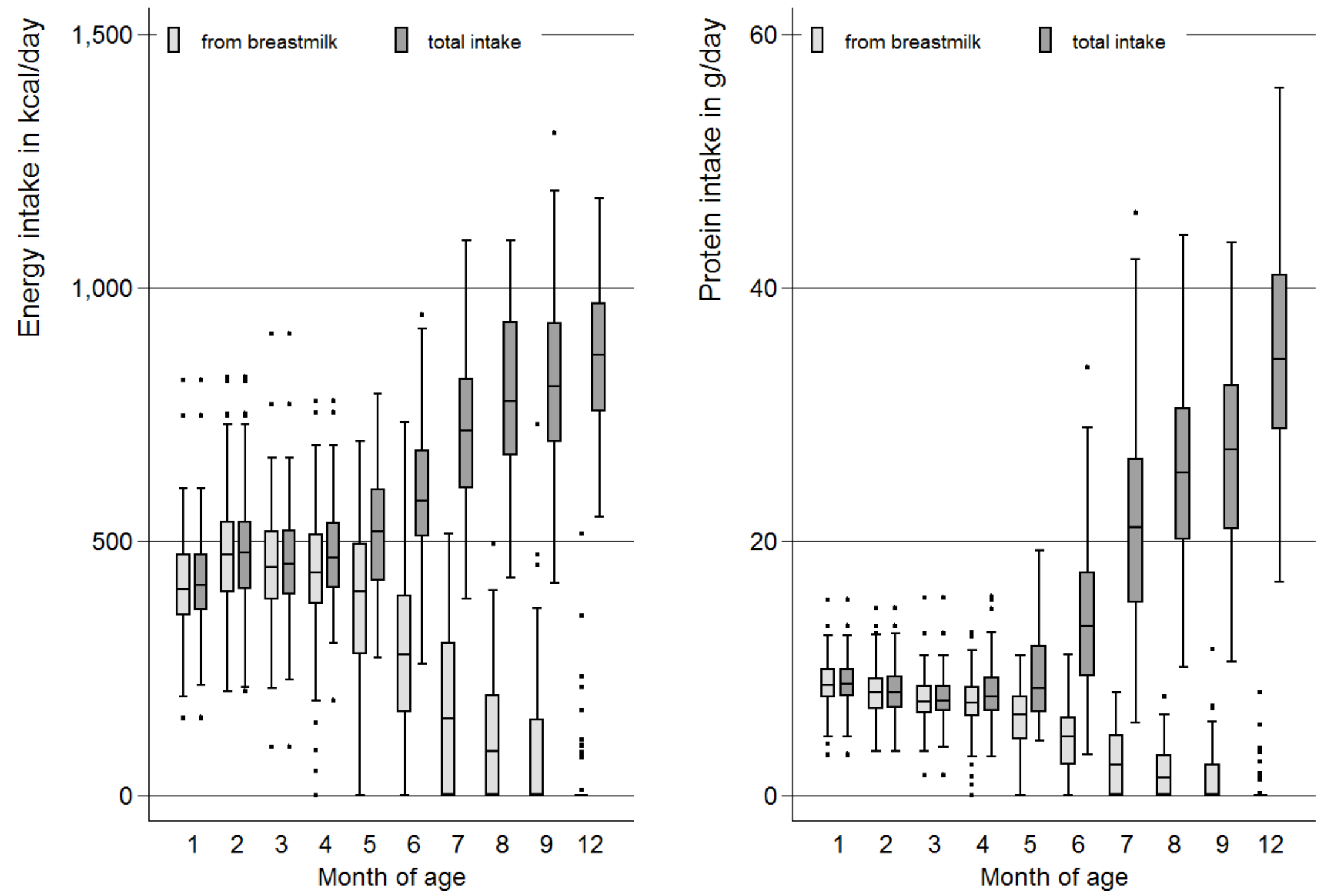
Figure 2: Percent of energy provided by carbohydrates, fat and protein from human milk and other foods in the first year of life

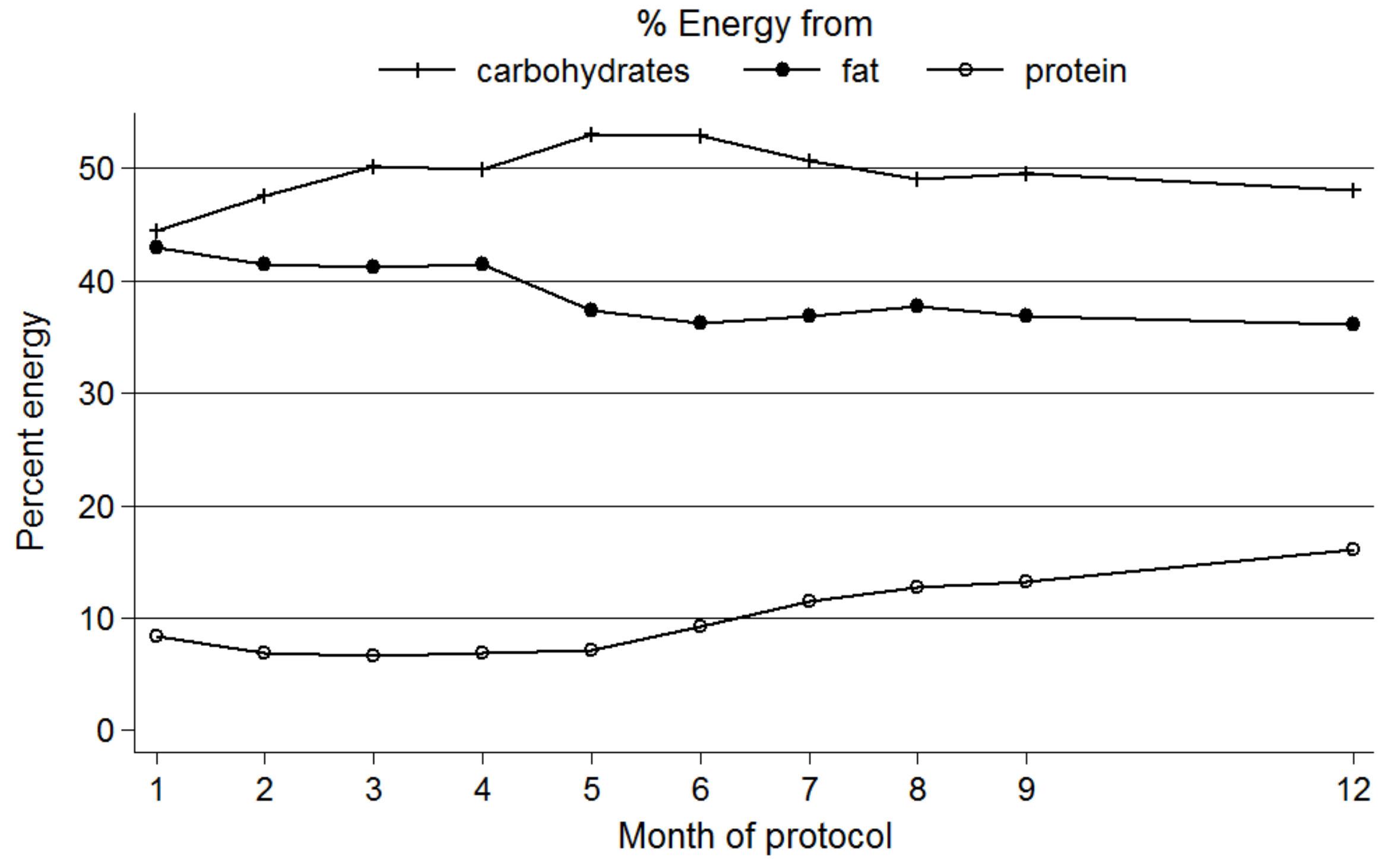


Table 1: General characteristics of 142 Italian breastfed children and mothers

\begin{tabular}{lrr}
\hline Gender & $\mathrm{n}$ & $\%$ \\
$\quad$ Male & 69 & 48.6 \\
Female & 73 & 51.4 \\
& & \\
Birthweight (grams) & & \\
& $3344(345)$ & \\
Gestational age & & \\
38 & & \\
39 & 32 & 22.5 \\
40 & 29 & 20.4 \\
41 & 41 & 28.9 \\
42 & 32 & 22.5 \\
& 8 & 5.6
\end{tabular}

Age of mother at birth (years) ${ }^{\star} \quad 32.4(4.4)$

Mother married?

$\begin{array}{lrr}\text { No } & 35 & 24.6 \\ \text { Yes } & 107 & 75.4\end{array}$

Mother's education level

$\begin{array}{lll}\text { no/low } & 18 & 12.7 \\ \text { Middle } & 92 & 64.8 \\ \text { High } & 32 & 22.5\end{array}$

BMI mother pre-pregnancy

$$
<20
$$

$20-<25$

$25-<30$

$>=30$

Smoking during pregnancy

No

Yes

$33 \quad 23.2$

Birth order

1st child $\quad 92 \quad 64.8$

2nd child $\quad 50 \quad 35.2$

Mother started to work postpartal $<=6$ months

No

$95 \quad 82.6$

Yes

$20 \quad 17.4$

Caesarean section

No

$111 \quad 78.2$

Yes

$31 \quad 21.8$

Ever EPDS\# > 12 at 2, 3 or 6 month

No

$118 \quad 89.4$

Yes

$14 \quad 10.6$

Nationality of parents

study country

one parent other country

$130 \quad 91.5$

both parents other country

$8-5.6$

$4 \quad 2.8$

Age at solid introduction

13-17 w.

17-21 w.

45.0

22-26 w.

33.3

$>26 \mathrm{w}$.

8.1

${ }^{*}$ mean (SD) \#Edinburgh postnatal depression score 
Table 2: Constituents of human milk from 30 mothers in the first 6 months of life. Mean with standard deviation.

\begin{tabular}{|c|c|c|c|c|c|}
\hline & \multicolumn{4}{|c|}{ Age in month } & \multirow{2}{*}{$\begin{array}{c}\text { Change in mean } \\
\text { over time } \\
p \text { value }\end{array}$} \\
\hline & 1 & 2 & 3 & 6 & \\
\hline Energy (kcal/100ml) & $66.1(11.1)$ & $68.3(13.4)$ & $63.0(10.5)$ & $62.4(13.3)$ & $0.065^{\circ}$ \\
\hline Carbohydrates (g/l) & $7.28(1.36)$ & $8.05(1.15)$ & $7.84(1.39)$ & $7.96(1.74)$ & 0.135 \\
\hline Lactose $(g / l)$ & $72.4(13.5)$ & $80.3(11.6)$ & $78.0(13.9)$ & $79.2(17.3)$ & 0.129 \\
\hline Glucose (g/l) & $0.24(0.08)$ & $0.24(0.06)$ & $0.26(0.07)$ & $0.25(0.06)$ & 0.503 \\
\hline Galactose (g/l) & $0.13(0.04)$ & $0.11(0.03)$ & $0.11(0.04)$ & $0.09(0.03)$ & $<0.001$ \\
\hline Protein (g/100ml) & $1.38(0.16)$ & $1.16(0.15)$ & $1.04(0.13)$ & $0.96(0.16)$ & $<0.001$ \\
\hline Non-protein nitrogen $(\mathrm{g} / \mathrm{dl})$ & $0.23(0.02)$ & $0.20(0.02)$ & $0.18(0.02)$ & $0.17(0.02)$ & $<0.001$ \\
\hline Fat $(g / 100 \mathrm{ml})$ & $3.20(1.27)$ & $3.16(1.18)$ & $2.92(1.23)$ & $2.71(1.25)$ & 0.164 \\
\hline SFA $^{1}$ & $39.0(5.62)$ & $37.7(4.38)$ & $37.2(4.82)$ & $36.8(4.64)$ & 0.202 \\
\hline MUFA $^{1}$ & $45.8(4.62)$ & $46.7(4.48)$ & $47.0(4.25)$ & $47.0(4.26)$ & 0.517 \\
\hline PUFA $^{1}$ & $15.2(4.26)$ & $15.6(2.95)$ & $15.7(3.43)$ & $16.3(4.17)$ & 0.530 \\
\hline 18:2n-6 (Linoleic acid) ${ }^{1}$ & $12.8(3.88)$ & $13.2(2.81)$ & 13.5 (3.32) & $14.0(4.08)$ & 0.435 \\
\hline 20:4n-6 (Arachidonic acid) ${ }^{1}$ & $0.51(0.16)$ & $0.52(0.13)$ & $0.52(0.10)$ & $0.52(0.15)$ & 0.981 \\
\hline 18:3n-3 ( $\alpha$-Linolenic acid) ${ }^{1}$ & $0.62(0.16)$ & $0.69(0.18)$ & $0.61(0.14)$ & $0.67(0.13)$ & 0.074 \\
\hline $20: 5 n-3\left(\right.$ EPA) ${ }^{1}$ & $0.12(0.03)$ & $0.12(0.03)$ & $0.10(0.03)$ & $0.12(0.05)$ & 0.090 \\
\hline 22:6n-3 (DHA) ${ }^{1}$ & $0.25(0.11)$ & $0.24(0.11)$ & $0.26(0.09)$ & $0.30(0.15)$ & 0.206 \\
\hline n-3 LC PUFA ${ }^{1}$ & $0.48(0.15)$ & $0.48(0.16)$ & $0.49(0.13)$ & $0.56(0.23)$ & 0.148 \\
\hline n-6 LC PUFA ${ }^{1}$ & $1.22(0.34)$ & $1.22(0.30)$ & $1.17(0.20)$ & $1.11(0.31)$ & 0.229 \\
\hline n-3 PUFA ${ }^{1}$ & $1.13(0.29)$ & $1.16(0.26)$ & $1.07(0.21)$ & $1.23(0.27)$ & 0.088 \\
\hline n-6 PUFA ${ }^{1}$ & $14.1(4.10)$ & $14.4(2.90)$ & $14.6(3.43)$ & $15.1(4.19)$ & 0.563 \\
\hline$n-3 / n-6$ ratio & $0.08(0.02)$ & $0.08(0.02)$ & $0.08(0.02)$ & $0.09(0.03)$ & 0.193 \\
\hline
\end{tabular}


\% fatty acid of milk total lipids; *based on linear random-effects model with subject as a random effect and month as fixed effect; ${ }^{\circ}$ linear trend 
Table 3: Number of children, energy and macronutrient intake in the first year of life (mean with SD)

\begin{tabular}{|c|c|c|c|c|c|c|c|c|c|c|}
\hline & & & & & Age in & nonth & & & & \\
\hline & 1 & 2 & 3 & 4 & 5 & 6 & 7 & 8 & 9 & 12 \\
\hline Number of infants & 126 & 117 & 108 & 96 & 88 & 85 & 73 & 68 & 74 & 77 \\
\hline HM intake (g/d) & $625(135)$ & $700(169)$ & $711(166)$ & $680(221)$ & 578 (299) & $437(279)$ & $273(258)$ & $180(200)$ & $141(215)$ & $43(132)$ \\
\hline HM intake $(g / d) \#$ & $\begin{array}{c}619 \\
(553,710) \\
\end{array}$ & $\begin{array}{c}700 \\
(593,787) \\
\end{array}$ & $\begin{array}{c}724 \\
(620,823) \\
\end{array}$ & $\begin{array}{c}695 \\
(597,813) \\
\end{array}$ & $\begin{array}{c}645 \\
(444,793) \\
\end{array}$ & $\begin{array}{c}477 \\
(257,613) \\
\end{array}$ & $243(0,480)$ & $138(0,317)$ & $0(0,240)$ & $0(0,0)$ \\
\hline Energy (kcal/d) & $419(99)$ & $481(121)$ & $456(111)$ & $474(97)$ & $513(116)$ & $589(140)$ & $717(161)$ & $779(160)$ & $813(174)$ & $860(145)$ \\
\hline Energy (kcal/kg/d) & - & - & $77(18)$ & - & - & $79(17)$ & - & - & - & $90(15)$ \\
\hline $\begin{array}{l}\text { Carbohydrates } \\
(\mathrm{g} / \mathrm{d})\end{array}$ & $46.3(10.7)$ & $57.1(14.1)$ & $56.9(14.2)$ & $59.2(12.3)$ & $68.1(15.8)$ & $77.7(19.7)$ & $90.7(23.0)$ & $95.6(24.4)$ & $100.5(24.3)$ & $103.8(25.0)$ \\
\hline $\begin{array}{l}\text { Carbohydrates } \\
(\mathrm{g} / \mathrm{kg} / \mathrm{d})\end{array}$ & - & - & $9.6(2.2)$ & - & - & $10.4(2.4)$ & - & - & - & $10.9(2.5)$ \\
\hline Protein $(\mathrm{g} / \mathrm{d})$ & $8.7(1.9)$ & $8.2(2.0)$ & $7.6(1.9)$ & $8.1(2.1)$ & $9.4(3.7)$ & $13.9(6.2)$ & $21.2(8.2)$ & $25.1(7.3)$ & $27.0(7.5)$ & $34.6(8.2)$ \\
\hline Protein $(\mathbf{g} / \mathbf{k g} / \mathrm{d})$ & - & - & $1.3(0.3)$ & - & - & $1.8(0.8)$ & & - & - & $3.6(0.9)$ \\
\hline Fat $(g / d)$ & $20.2(6.4)$ & $22.3(6.6)$ & $21.0(6.4)$ & $21.8(4.5)$ & $21.3(5.1)$ & $23.7(6.9)$ & $29.4(7.8)$ & $32.5(8.4)$ & $33.3(8.6)$ & $34.2(6.8)$ \\
\hline Fat $(g / k g / d)$ & - & - & $3.5(1.1)$ & - & - & $3.2(0.9)$ & - & - & - & $3.6(0.8)$ \\
\hline$\%$ E Carbohydrates & $44.5(5.2)$ & $47.6(3.4)$ & $50.2(5.4)$ & $49.9(1.7)$ & $53.0(3.2)$ & $52.9(6.1)$ & $50.7(6.3)$ & $49.1(6.7)$ & $49.5(5.9)$ & $48.0(6.7)$ \\
\hline \% E Protein & $8.4(1.0)$ & $6.8(0.8)$ & $6.7(0.6)$ & $6.8(0.9)$ & $7.2(1.8)$ & $9.2(3.0)$ & $11.6(3.0)$ & $12.8(2.1)$ & $13.2(2.2)$ & $16.1(2.6)$ \\
\hline$\%$ E Fat & $43.0(5.8)$ & $41.4(4.0)$ & $41.2(6.2)$ & $41.5(1.6)$ & $37.4(3.0)$ & $36.2(5.9)$ & $36.8(5.1)$ & $37.7(6.1)$ & $36.9(5.3)$ & $36.1(6.0)$ \\
\hline
\end{tabular}

\# median with interquartile range in brackets. $\% E$ = percent energy. $d$ = day 
Table 4: Daily intake of fatty acids from breast milk in mg (SD)

\begin{tabular}{|c|c|c|c|c|}
\hline & \multicolumn{4}{|c|}{ Age in month } \\
\hline & 1 & 2 & 3 & 6 \\
\hline SFA $^{1}$ & 7420.3 (2425.5) & $7911.4(2398.4)$ & $7344.1(2390.0)$ & $4205.1(3107.4)$ \\
\hline MUFA $^{1}$ & 8712.8 (2998.6) & $9821.8(3115.3)$ & $9238.6(2974.8)$ & $5344.3(3953.1)$ \\
\hline PUFA $^{1}$ & $2851.5(913.8)$ & $3278.8(1063.0)$ & $3082.1(999.4)$ & $1884.8(1454.4)$ \\
\hline 18:2n-6 (Linoleic acid) ${ }^{1}$ & $2407.0(767.2)$ & $2764.9(915.0)$ & 2635.1 (859.7) & 1619.5 (1275.4) \\
\hline 20:4n-6 (Arachidonic acid) ${ }^{1}$ & $95.6(32.9)$ & $109.6(38.6)$ & $101.1(33.1)$ & $58.7(43.5)$ \\
\hline 18:3n-3 ( $\alpha$-Linolenic acid) ${ }^{1}$ & $118.8(47.7)$ & $144.7(49.0)$ & $118.8(39.1)$ & $76.8(58.2)$ \\
\hline $20: 5 n-3(E P A)^{1}$ & $22.7(9.23)$ & $24.2(7.90)$ & $20.4(6.45)$ & $14.1(10.77)$ \\
\hline 22:6n-3 (DHA) ${ }^{1}$ & $48.5(25.5)$ & $51.3(20.2)$ & $50.3(17.1)$ & $32.7(23.4)$ \\
\hline n-3 LC PUFA ${ }^{1}$ & $92.3(42.9)$ & $101.2(36.8)$ & $95.0(30.8)$ & $62.2(44.1)$ \\
\hline n-6 LC PUFA ${ }^{1}$ & $228.7(75.4)$ & $256.9(86.5)$ & $229.7(72.7)$ & $126.3(92.2)$ \\
\hline n-3 PUFA ${ }^{1}$ & $215.9(85.2)$ & $244.1(81.6)$ & $209.6(66.1)$ & $138.9(99.5)$ \\
\hline n-6 PUFA ${ }^{1}$ & $2635.7(836.0)$ & 3021.8 (990.9) & $2865.0(927.9)$ & $1745.8(1362.9)$ \\
\hline
\end{tabular}

